\title{
Impurity re-distribution in the corner regions of the JET divertor
}

\author{
A Widdowson ${ }^{1}$, J P Coad ${ }^{1}$, E Alves ${ }^{2}$, A Baron-Wiechec ${ }^{1}$, NP Barradas ${ }^{3}$, N Catarino ${ }^{2}$, \\ V Corregidor $^{2}$, K Heinola ${ }^{4}$, S Krat ${ }^{5,6}$, J Likonen ${ }^{7}$, GF Matthews ${ }^{1}$, M Mayer ${ }^{6}$, P. \\ Petersson ${ }^{8}, \mathrm{M} \mathrm{Rubel}^{8}$ and JET Contributors* \\ EUROfusion Consortium, JET, Culham Science Centre, Abingdon, OX14 3DB, UK \\ ${ }^{1}$ Culham Centre for Fusion Energy, Culham Science Centre, Abingdon, OX14 3DB, \\ UK \\ ${ }^{2}$ Instituto Superior Técnico, Universidade de Lisboa, 1049-001 Lisboa, Portugal \\ ${ }^{3} \mathrm{C} 2 \mathrm{TN}$, Instituto Superior Técnico, Universidade de Lisboa, 2695-066 Lisboa, \\ Portugal \\ ${ }^{4}$ University of Helsinki, P.O. Box 64, 00560 Helsinki, Finland \\ ${ }^{5}$ National Research Nuclear University MEPhI, 115409 Kashirskoe Highway, \\ Moscow, Russia \\ ${ }^{6}$ Max-Planck Institut für Plasmaphysik, 85748 Garching, Germany \\ ${ }^{7}$ VTT Technical Research Centre of Finland, P.O. Box 1000, FIN-02044 VTT, \\ Finland \\ ${ }^{8}$ Royal Institute of Technology, SE-10044 Stockholm, Sweden \\ *See the author list of "Overview of the JET results in support to ITER" by X. \\ Litaudon et al. to be published in Nuclear Fusion Special issue: overview and \\ summary reports from the 26th Fusion Energy Conference (Kyoto, Japan, 17-22 \\ October 2016) \\ Email: anna.widdowson@ukaea.uk
}

\begin{abstract}
The International Thermonuclear Experimental Reactor (ITER) will use a mixture of deuterium (D) and tritium (T) as the fuel to generate power. Since $\mathrm{T}$ is both radioactive and expensive the Joint European Torus (JET) has been at the forefront of research to discover how much $\mathrm{T}$ is used and where it may be retained within the main reaction chamber. Until the year 2010 the JET plasma facing components were constructed of carbon fibre composites (CFC). During the JET carbon (C) phases impurities accumulated at the corners of the divertor located towards the bottom of the chamber in regions shadowed from the plasma where they are very difficult to reach and remove. This build-up of $\mathrm{C}$ and the associated H-isotope (including T) retention were of particular concern for future fusion reactors therefore, in 2010 JET changed the wall protection to (mainly) Be and the divertor to tungsten (W) - the JET ITER-like Wall (ILW) - the choice of materials for ITER. This paper reveals that with the JET ILW impurities are still accumulating in the shadowed regions, with Be being the majority element, though the overall quantities are very much reduced from those in the $\mathrm{C}$ phases. The strike points for corner discharges are the principle source of the material transporting into the
\end{abstract}


shadowed regions, but particles typically have about a $75 \%$ probability of reflection from lineof sight surfaces, and multiple reflection/scattering results in deposition over all surfaces.

Keywords: JET divertor, beryllium, impurities, deposition

PACS: $52.40 \mathrm{H}$

\section{Introduction}

The Joint European Torus (JET) is the largest operating tokamak in the world, and is used to study scenarios and probable behaviour of the next stage in fusion power development, the International Thermonuclear Experimental Reactor (ITER). ITER will use a mixture of deuterium (D) and tritium (T) as the fuel to generate power, and since $\mathrm{T}$ is both radioactive and expensive JET has been at the forefront of research to discover how much $\mathrm{T}$ is used and where it may be retained within the main reaction chamber. In tokamaks there is inevitably some erosion of the components surrounding the plasma by plasma ions or chargeexchange neutrals $(\mathrm{CXN})$, and this material will travel to other locations where it may co-deposit with the hydrogenic plasma fuel. Important issues for ITER, which will be fuelled with a deuterium (D)/tritium (T) mixture, are the amount of $\mathrm{T}$ that may be trapped by this process, and the accessibility of the major deposits. In both JET and ITER the primary plasma interaction areas are in the divertor towards the bottom of the chamber - Figures 1(a) and 1(b) are cross-sections of the JET and ITER divertors, respectively.

Figure 1(b) (which is on a much smaller scale than 1(a)), shows that there are also locations in the ITER divertor corners where impurities might accumulate. Until the year 2010 the JET divertor was constructed of carbon fibre composites (CFC), as was the plan for ITER - the main chamber wall of JET was also protected with CFC tiles, though this protection is planned to be of beryllium (Be) in ITER. In the
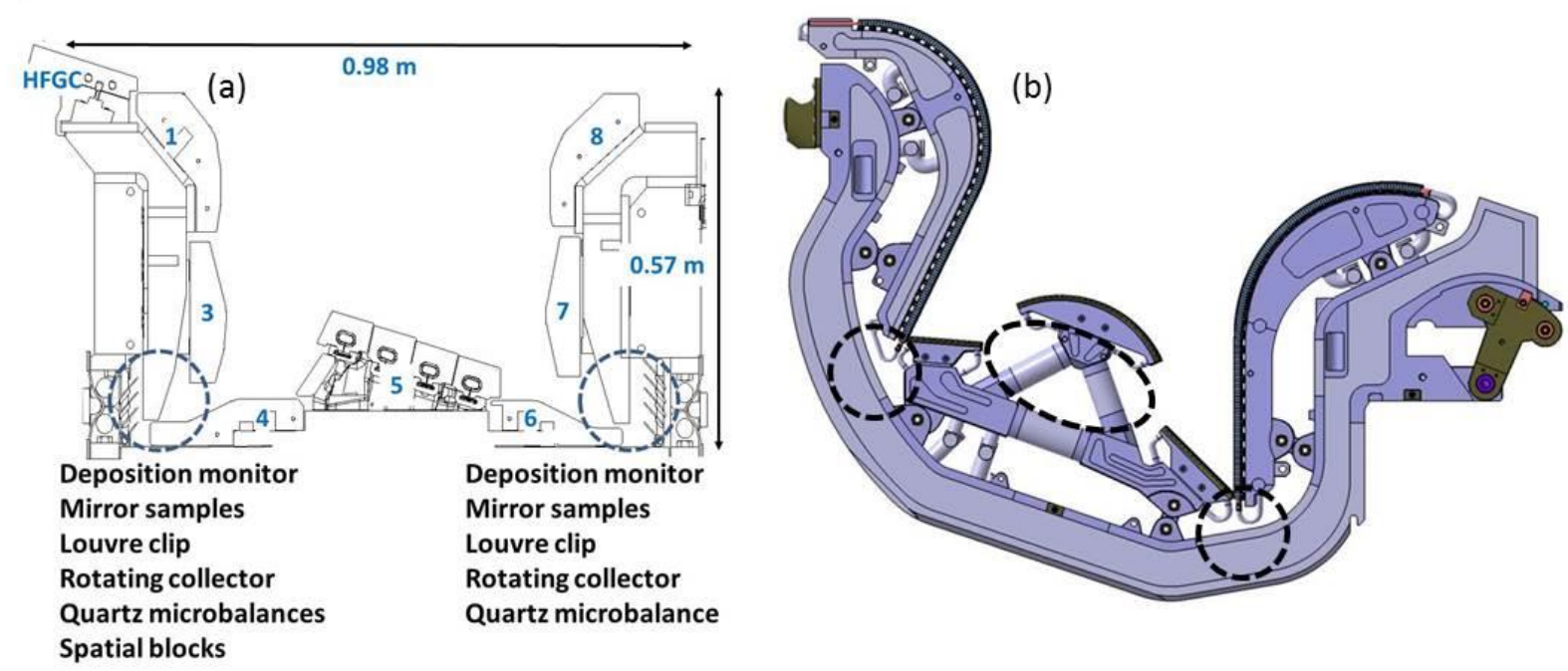

Figure 1. (a) The cross-section of the JET divertor is shown with the diagnostics installed in the inner and outer divertor corners since 2004 listed, (b) The cross-section of the ITER divertor. Remote areas for both divertor structures are indicated with dashed circles. 
experiments at JET in 1996 in preparation for the D-T campaign the following year (DTE1) it was discovered that the largest deposits were at the inner corner of the divertor, in areas shadowed from direct plasma interaction [1]. Following DTE1, despite exhaustive efforts to remove $\mathrm{T}$ by running discharges in $\mathrm{H}$ or $\mathrm{D}$ and venting the vessel to air, over $6 \mathrm{~g} \mathrm{~T}$ remained trapped in the vessel, and over half of that had travelled to inaccessible regions at the inner divertor corner [2]. In tokamaks with predominantly carbon-based plasma-facing components (PFC), material is eroded (primarily) from the main chamber and is transported through the scrape-off layer (SOL) to the inner divertor tiles: from there the carbon migrates under the plasma action towards the inner corner of the divertor until it reaches a remote region beyond plasma interaction. In other JET divertor configurations used since 1998 the carbon flux to the inner corner has reduced somewhat, but deposition has developed at the outer divertor corner [3]. This deposition of impurities in the remote corners of JET (and the trapping of T) influenced the change of ITER divertor material from carbon to tungsten (W).

The ITER-like Wall was installed in JET in 2010 precisely to indicate the likely behaviour with the (then only proposed) ITER mix of materials; a beryllium (Be) main chamber wall and a $\mathrm{W}$ divertor [4]. The overall migration to the corner regions of JET has reduced by more than an order of magnitude, with a concomitant reduction in retained deuterium [5][6]. Nevertheless, although the deposition is now mostly Be, there are still complex sputtering and re-deposition mechanisms occurring within these regions which are shadowed from any plasma ions that may well determine the sinks for $\mathrm{T}$ in ITER, and little is known about the detailed mechanisms involved. JET installed many

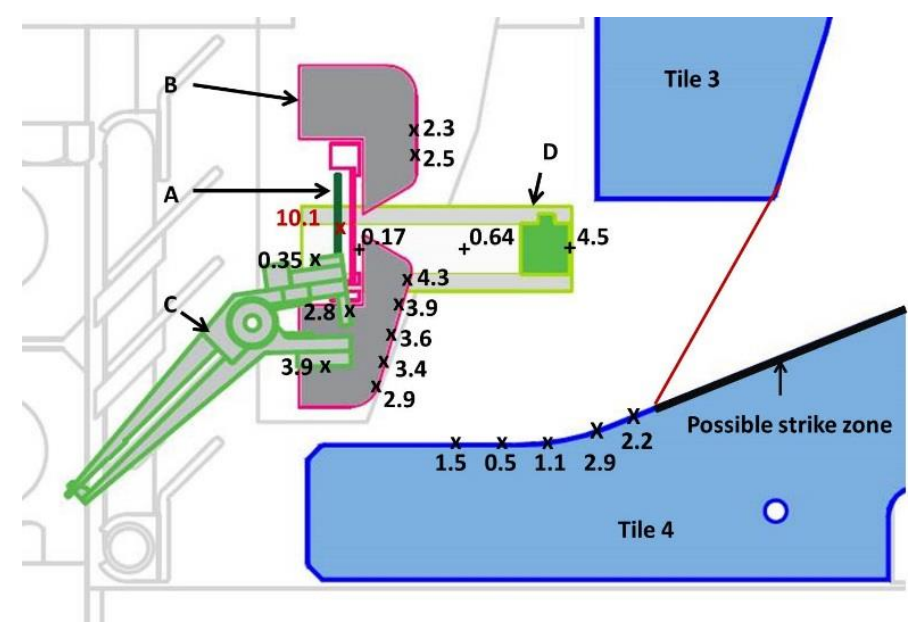

Figure 2. Beryllium concentrations (in units of $10^{18}$ atoms $\mathrm{cm}^{-2}$ ) at points on the surfaces of components within the shadowed region at the inner corner of the JET divertor after ILW1. The deposition monitor box (A), its cover (B), the louvre clip (C) and mirror cassette (D) are indicated. 
diagnostics in these regions from 2004 onwards [7], but this is the first attempt to describe the complex deposition effects observed; the data are restricted to the ILW campaigns most relevant for ITER.

\section{Experimental data}

\subsection{Results from 2011-2012 JET operations}

Figure 1(a) shows the cross-section of the JET divertor with the diagnostics installed in the inner and outer divertor corners since 2004 listed [7]. Figure 2 gives the amount of Be in units of $10^{18}$ atoms $\mathrm{cm}^{-2}$ analysed within the deposition monitor box (A) [8][9], on the surface of its cover (B), on a louvre clip (C), and on mirror samples from within a cassette ('pan pipes')(D) [10] that were all located at the inner divertor corner during ILW-1. Also present were Quartz Microbalances (QMB) [11], a Rotating Collector [12][13][14] and spatial blocks (not shown). The diagnostics are shown superimposed to indicate their relative radial position, but in reality they are each at different toroidal locations. All these diagnostics were designed to provide some degree of time resolution, be it per operational period (Louvre clips, spatial blocks), of a few pulses (Rotating Collectors), or of a single pulse or part of a pulse (QMB); the principal objective for the pan pipes was to measure how much mirror reflectivity degraded per operational period. However, for this paper the data of interest are the

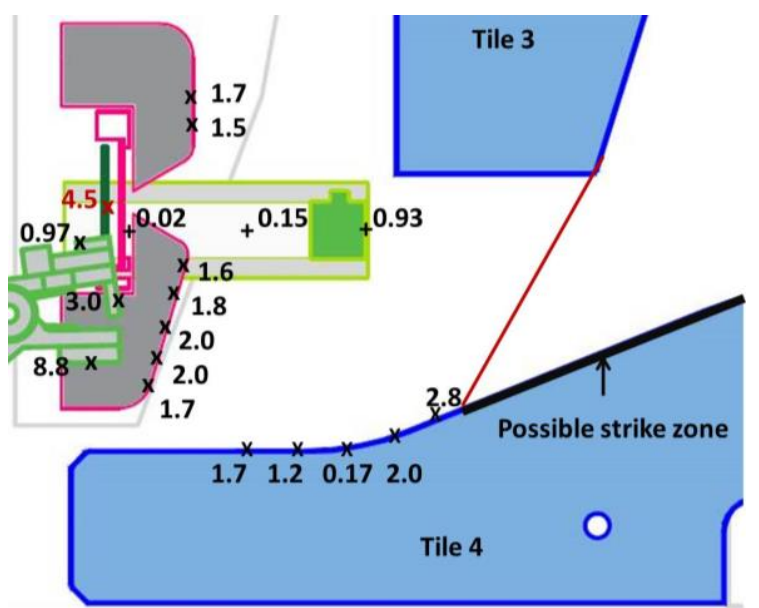

Figure 3. Carbon concentrations (in units of $10^{18}$ atoms $\mathrm{cm}^{-2}$ ) at points on the surfaces of components within the shadowed region at the inner corner of the JET divertor after ILW1

amounts of deposition that have accrued on all the component surfaces per operational period. Included in the data set are the analyses on divertor tile surfaces that border the shadowed regions.

It is clear that the impurities depositing in the corner region have come from surfaces interacting with the plasma, and as such the 2D ERO code defines the plasma-accessible boundary for the inner divertor as vertically down from the bottom of the plasma-facing surface of Tile 3 to the intersection 
with the surface of Tile 4 [15]. However, due to the angle of the field lines, plasma is able to reach part of the sloping region of Tile 4, and we define the plasma boundary as per the red line in figure 2, which agrees with the envelope of strike point distribution [16]. Furthermore, the sloping part of Tile 4 exposed to the plasma is in fact the strike point for many of the discharges during ILW1, so is the likely source of impurities flowing across the boundary. Figure 3 shows the same analysis points, but with the amounts of $\mathrm{C}$ in units of $10^{18}$ atoms $\mathrm{cm}^{-2}$. Analysis points for both figures are shown on the following locations: three mirrors (in different channels of the multi-channel cassette, only one of which is shown in each Figure), three surfaces of the louvre clip, the shadowed region of Tile 4, the cover of the deposition monitor, and within the deposition monitor itself (in a larger font size).

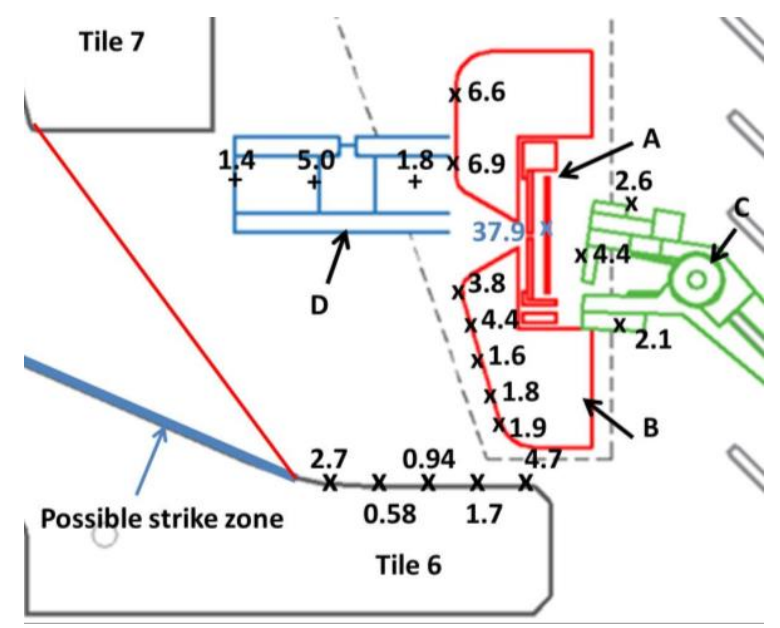

Figure 4. Be concentrations (in units of $10^{18}$ atoms $\mathrm{cm}^{-2}$ ) at points on the surfaces of components within the shadowed region at the outer corner of the JET divertor after ILW1. The deposition monitor box (A), its cover (B), the louvre clip (C) and mirror cassette (D) are indicated.

The best indicator of particle flux into each region is the deposition monitor, since it traps the flux within an almost closed box (entrance slit is just $0.8 \mathrm{~mm}$ wide), and it also gives an indication of sticking coefficients [8][9]. Furthermore, the exact location of the peak in the primary deposit within the monitor box can be traced back through the slot to indicate the source of the particle flux: for the Be shown in figure 2 the source is clearly the strike point region on Tile 4 . The amount of Be collected within the monitor box was $10.1 \times 10^{18}$ atoms $\mathrm{cm}^{-2}$, the average Be concentration on the cover was $\sim 3.3 \times 10^{18}$ atoms cm$~^{-2}$, whilst at the front of the louvre clip was $\sim 2.8 \times 10^{18}$ atoms $\mathrm{cm}^{-2}$. This suggest about $60-70 \%$ of the flux to these exposed surfaces was re-sputtered or reflected, which is in line with the sticking coefficient [9] found within the box where $~ 40 \%$ of the incoming flux was located in the slit image, the rest being reflected or re-sputtered at least once (but trapped within the 
box). The data for $\mathrm{C}$ shown in figure 3 give about a $50 \%$ reduction between the monitor box $(4.5 \times$ $10^{18}$ atoms $\mathrm{cm}^{-2}$ ) and the values on the deposition monitor cover and louvre clip, which was also the

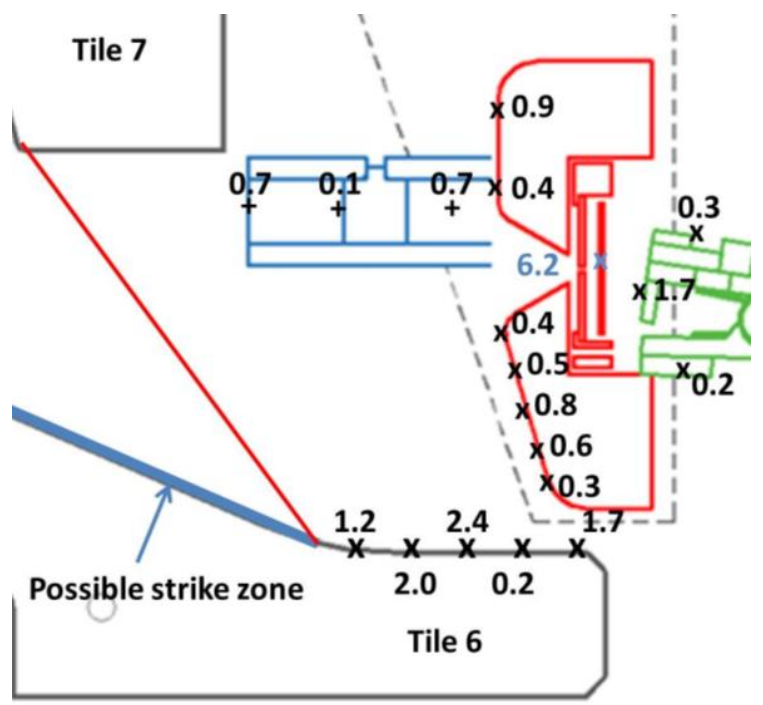

Figure 5. C concentrations (in units of $10^{18}$

atoms $\mathrm{cm}^{-2}$ ) at points on the surfaces of

components within the shadowed region at the

outer corner of the JET divertor after ILW1.

sticking coefficient for the flux re-distributed within the box. However, tracing back from the $\mathrm{C}$ image through the slit shows the dominant source is actually the back of Tile 3: Since this material is probably chemically sputtered by hydrogen rather than by energetic plasma ions, the particles may have less kinetic energy and be less likely to re-sputter or reflect at the deposition monitor.

Deposit is found on all three inner louvre clip surfaces even though only one of the three faces has a line of sight to the plasma erosion zone. In fact there is some deposition all over the blades of the louvre clips (which fit between, and secure the clip to, a louvre) as was observed by the interference patterns on them and this illustrates that multiple re-erosion events occur resulting in deposition all over the complex corner structures. Deposition also occurs on the shadowed part of Tile 4. Deposits of hundreds of microns of $\mathrm{C}$ (containing high concentrations of $\mathrm{D}$ ) were found in this region during pre-2010 phases of JET (JET-C), but migration to this region is greatly reduced with the ILW now the principal plasma impurity is $\mathrm{Be}[5]$.

Diagnostics present at the outer divertor corner and the associated analysis points for $\mathrm{Be}$ and $\mathrm{C}$ are shown in units of $10^{18}$ atoms $\mathrm{cm}^{-2}$ in figures 4 and 5, respectively. The energy flux to the outer divertor corner is significantly greater than to the inner corner, and surface temperatures are probably higher as a result. The deposition monitor data shows a greater impurity flux to the outer corner [9], as do the rotating collectors [17]. As an indication of the extent of primary erosion of the incoming flux, the outer monitor indicated a flux of Be of $17.5 \times 10^{18}$ atoms $\mathrm{cm}^{-2}$ over the ILW1 campaign, yet the 
values at the front face of the louvre clip and on the deposition monitor cover are about a factor of 4 lower. This indicates that about $75 \%$ of the Be arriving at the exposed surfaces is re-sputtered or reflected from the surface, again in line with the sticking coefficient $(0.33)$ found within the monitor box [9].

There is an interesting variation in the residual amounts of $\mathrm{Be}$ on the exposed surfaces, with less than $2 \times 10^{18}$ atoms $\mathrm{cm}^{-2}$ at the bottom of the deposition monitor cover, an average of $4.2 \times 10^{18}$ atoms cm $\mathrm{c}^{-2}$ just below the slit plus on the front of the louvre clip, and $6.6 \times 10^{18}$ atoms $\mathrm{cm}^{-2}$ at the top of the cover. If, as postulated, the strike point region on Tile 6 is the sputtering source of the Be, then the Be should leave the surface with a cosine distribution about the normal to the surface. If the three data points are at average angles of 20, 45 and 75 degrees to the surface, the fluxes should be in the ratios 2.0:4.2:5.7, respectively, normalising to the middle value, giving a not dissimilar ratios to the experimental data. As at the inner corner, the sides of the louvre clip not facing the plasma have some deposit, and there is evidence from the interference colours of deposition on the louvre blades.

\subsection{Results from 2014-15 JET operations}

A large number of components were also removed and analysed after the second ILW operational period (ILW2). Unfortunately, no deposition monitors were mounted in this period, but some effort has been made to measure $\mathrm{Be}$ and $\mathrm{C}$ on surfaces not in direct line of sight from the strike zones (in addition to the louvre clips). Figure 6 shows the $\mathrm{Be}$ and $\mathrm{C}$ analyses on components from the inner divertor corner; the $\mathrm{C}$ amounts are given in italics. More pulses were run with the strike point at the inner divertor corner during ILW2 than during ILW1 [16], so more material might be expected to have travelled to the adjacent shadowed region. The only clear evidence of increased deposition, however, is the amount of deposition on the shadowed part of Tile 4. 


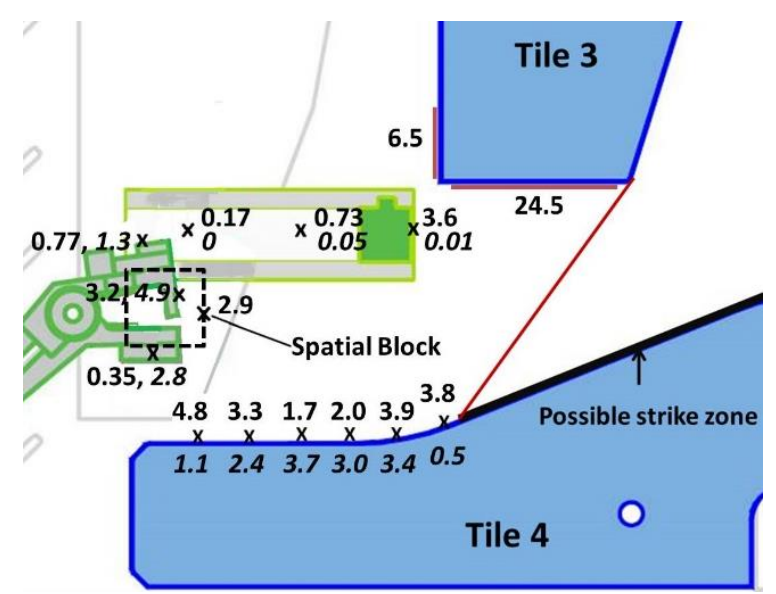

Figure 6. Be and $\mathrm{C}$ concentrations (in units of $10^{18}$ atoms $\mathrm{cm}^{-2}$ ) at points on the surfaces of components within the shadowed region at the inner corner of the JET divertor after ILW2; the $\mathrm{C}$ amounts are given in italics.

Although no DM was present, there was an $\mathrm{RC}$ present. The $\mathrm{RC}$ collector is in a similar radial location to a DM and also has a collector behind a slit. However, the slit on the RC is $2 \mathrm{~mm}$ wide (compared to $0.8 \mathrm{~cm}$ for the DM), and the gap from slit to collector is smaller; both these factors will make the RC a less efficient collector of the primary flux. The integrated deposition of Be on the RC collector was $4.9 \times 10^{18}$ atoms $\mathrm{cm}^{-2}$ over the ILW2 campaign [14], which is about 1.5 times greater than the deposit on the front mirror and the louvre clip, but less than the factor between these points and the DM following ILW1 ( x2.5, see Figure 2).

Additional examples of surfaces analysed after ILW2 are the ends of Tile 3 and 7 (note, however that these tiles were exposed to both ILW1 and ILW2), and four sides of a witness sample (termed a "spatial block") mounted at the inner corner. The bottom of Tile 3 had an average Be deposit of 24.5

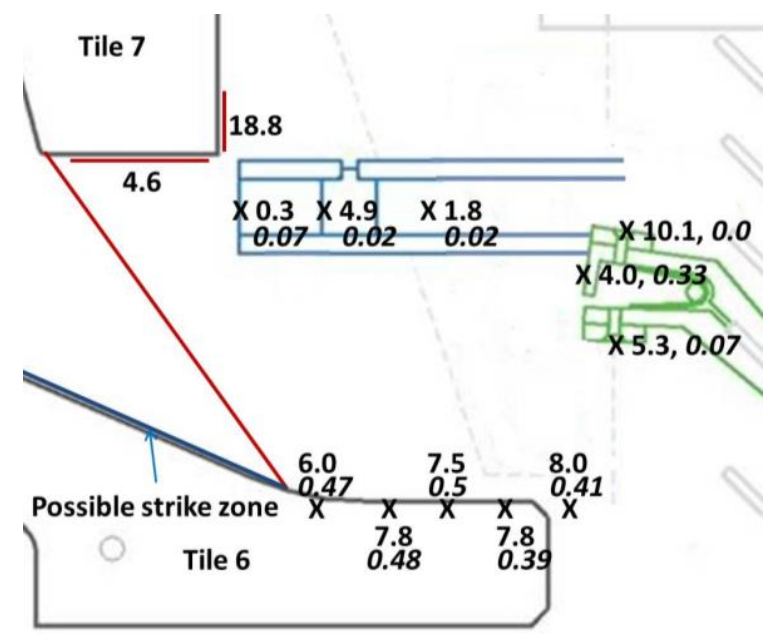

Figure 7. Be and $\mathrm{C}$ concentrations (in units of

$10^{18}$ atoms $\mathrm{cm}^{-2}$ ) at points on the surfaces of

components within the shadowed region at the

outer corner of the JET divertor after ILW2; the

$\mathrm{C}$ amounts are given in italics. 
$\times 10^{18}$ atoms $\mathrm{cm}^{-2}$ : this tile would be exposed to the maximum flux of material eroded from the strike zone according to the cosine rule. However, what is interesting is that $6.5 \times 10^{18}$ atoms cm$~^{-2} \mathrm{Be}$ are found on the rear surface of the tile, which can only result from multiple sputtering events. Since the tiles are made of CFC (coated with $\mathrm{W}$ on the front face only), the level of $\mathrm{C}$ deposition cannot be ascertained. The spatial block is a stainless steel cube with $15 \mathrm{~mm}$ sides bolted to the side of one of the carrier fins. Its position is indicated by the dashed square in figure 6 , with the Be and $\mathrm{C}$ levels on its plasma-facing side shown. The analyses of the other faces are not shown to avoid confusion, but the bottom and top faces had amounts of 0.79 and $0.90 \times 10^{18}$ atoms $\mathrm{cm}^{-2} \mathrm{Be}$, and the side face (i.e. in the plane of the drawing) $1.16 \times 10^{18}$ atoms $\mathrm{cm}^{-2}$. The corresponding figures for the $\mathrm{C}$ deposition are $1.04,1.62$ and $1.4 \times 10^{18}$ atoms $\mathrm{cm}^{-2}$.

Be and $\mathrm{C}$ data from the outer corner of samples analysed after exposure during ILW2 are given in figure 7. The values for Be for comparable points facing the plasma vary relative to ILW1: The front mirror value is down, the front louvre clip value is about the same, and the shadowed part of Tile 6 has higher levels. The integrated deposit of $\mathrm{Be}$ on the $\mathrm{RC}$ at the outer corner was $18 \times 10^{18}$ atoms cm${ }^{-2}$ which is a factor of $\sim 5$ greater than the louvre clip [14]. This may be compared with the DM value for ILW1 $\left(37.9 \times 10^{18}\right.$ atoms $\left.\mathrm{cm}^{-2}\right)$, though an even larger value would have been expected following ILW2. What is clear is that the side faces of the louvre clip has greatly increased Be levels, and there is a lot of Be on the back face of Tile 7. This suggests that re-sputtering effects are stronger than they were for ILW1. The $\mathrm{C}$ values are all low following ILW2; it may be that residual $\mathrm{C}$ in the JET vessel had been reduced during ILW1, and there was less C getting into the plasma during ILW2, or that the Be deposition in the shadowed regions has coated over the (carbon) tile surfaces.

\section{Discussion}

During the JET-C operational campaigns the assumption has been that the main mechanism driving the migration of carbon to the shadowed region of the inner divertor was chemical sputtering [2][3]. The principal evidence for this is that carbon was preferentially removed from the primary plasma impurity deposition sites on Tiles 1 and 3 and the HFGC tile (following its installation from 2004 onwards), leaving behind Be and other metals. The deposits within the shadowed region (notably on the shadowed part of Tile 4) were almost pure carbon with high D contents. During the latter JET-C campaigns there was also migration of $\mathrm{C}$ into the outer corner, indeed deposition monitors installed 2007-9 showed that the fluence into the outer corner was at least as large as that into the inner corner, but precise numbers were difficult as the thickest film (the slit image) had spalled off [8]. The surface loss probability for the carbon was even higher than the values after ILW1, being $70-80 \%$ for the inner monitor, resulting in distributions less peaked about the slit image.

Unlike the inner divertor though, there has never been significant plasma impurity deposition on Tiles 7 and 8 in JET nor on tiles further outboard - in fact these tiles are net erosion zones. During these 
latter JET-C phases, an increasing Be content was observed on Tiles 4 and 7 [3]. It is unclear why increasing amounts of $\mathrm{Be}$ were travelling to the corner regions during this time. It may be that the $\mathrm{Be}$ concentration in, and thickness of, the deposits on Tiles 3 and 4 had reached such a level that the reflective properties of the layers had marginally changed, allowing some Be to migrate to Tile 4 . The same argument cannot be used for Be deposition on Tile 6 (since Tiles 7 and 8 do not have any deposits), unless Tiles 1 and 3 are also the source of the Be on Tile 6 by migration across the divertor (which was suggested from QMB data [18]). The Be build-up on Tiles 4 and 6 may have occurred by preferential chemical sputtering of $\mathrm{C}$ in the same way as on Tiles 1 and 3 . The Be levels in the deposition monitors were extremely low, and with a uniform distribution over top and bottom plates [8]. It was clear from photographs and from practical handling experience that within both inner and outer shadowed regions the carbon was widely spread, and was by no means limited to surfaces with a line of sight to the entrance to the shadowed zone - however no samples were taken for analysis.

During the ILW operational periods Be has become the principal plasma impurity and the main deposition site is at the top of Tile 1 and the HFGC tiles. Although there have been a mix of plasma configurations during the ILW periods similar to the JET-C years, the primary deposition has been concentrated deeper into the scrape-off layer (SOL) than for JET-C, i.e. on the HFGC tile and the very top of Tile 1 . There has been little evidence of migration from this primary deposition site towards the corner, since only low levels of Be have accumulated on Tile 3 and 4. On the other hand, however, significant amounts of Be have been measured on components in the shadowed regions, and, as for $\mathrm{C}$ during JET-C, also on surfaces with no direct line of sight to the plasma. There is a possible explanation for the restriction of deposition to the deeper parts of the SOL, the limited deposition on Tiles 3 and 4, and the flux of Be into the shadowed regions. High-Z materials reflect more effectively than low-Z materials [19], so there may be an energy above which the Be ions in the SOL nearer the last closed flux surface (LCFS) are being reflected (or sputtered) from the metallic surface (which is W-coated CFC, in contrast to the carbon surface during JET-C phases). This Be can proceed in a stepwise progression until it reaches the strike point, from where Be atoms can be launched into the shadowed region.

\section{Conclusions}

JET has been collecting data that may be indicative of behaviour in the future ITER machine since its inception. In particular, massive migration of $\mathrm{C}$ into shadowed regions of the JET divertor (and trapping of T therein) observed during preparations for the DTE1 JET experiment in 1997 was of concern for ITER, which has similar shadowed regions in the corner of the divertor. This ultimately influenced the change of ITER design to a $\mathrm{W}$ divertor instead of C. JET has changed its plasma-facing components to use the same material mix of Be wall and $\mathrm{W}$ divertor as now planned for ITER, and this JET-ILW configuration has demonstrated a reduction by more than an order of magnitude in 
impurities being transported to the inner divertor: these impurities are now predominantly Be rather than C. However, Be is now being deposited in the shadowed corners of the divertor instead of $\mathrm{C}$, albeit in much reduced quantities. Mechanisms appear to be similar:

- Primary sources of the impurities entering the shadowed regions according to deposition monitors are the strike points on Tiles 4 and 6

- Surface loss probabilities on primary impact of these impurities are very high (60-80\%)

- Multiple erosion effects leading to deposition over surfaces with no line of sight to the source

- Retention of $\mathrm{D}$ (as proxy for $\mathrm{T}$ ) within the deposits

During JET-C the Be component of the impurities in the SOL (dominated by C) was deposited on the CFC Tiles 1 and 3 (and latterly also HFGC). The Be is now being deposited deeper into the SOL (Wcoated HFGC tile and Tile 1) where ion energies are lower. Be ions arriving at the divertor closer to the LCFS with higher energy have a greater probability of sputtering/reflection from $\mathrm{W}$ so that they are able to travel to the strike points on Tiles 4 and 6 and then be sputtered as neutrals into the shadowed zone.

\section{Acknowledgements}

This work has been carried out within the framework of the EUROfusion Consortium and has received funding from the Euratom research and training programme 2014-2018 under grant agreement No 633053 and from the RCUK Energy Programme [grant number EP/P012450/1]. To obtain further information on the data and models underlying this paper please contact PublicationsManager@ccfe.ac.uk. The views and opinions expressed herein do not necessarily reflect those of the European Commission. 


\section{References}

[1] A.T. Peacock, P. Andrew, P. Cetier, J.P. Coad, G. Federici, F.H. Hurd, M.A. Pick, C.H. Wu, J. Nucl. Mater. 266-269 (1999) 423-428.

[2] J.P. Coad, N. Bekris, J.D. Elder, S.K. Erents, D.E. Hole, K.D. Lawson, G.F. Matthews, R.-D. Penzhorn, P.C. Stangeby, J. Nucl. Mater. 290-293 (2001) 224-230.

[3] J.P. Coad, S. Gruenhagen, D.E. Hole, A. Hakola, S. Koivuranta, J. Likonen, M. Rubel, A. Widdowson, JET-EFDA contributors, Phys. Scr. T145 (2011) 014003.

[4] G.F. Matthews, M. Beurskens, S. Brezinsek, M. Groth, E. Joffrin, A. Loving, M. Kear, M.-L. Mayoral, R. Neu, P. Prior, V. Riccardo, F. Rimini, M. Rubel, G. Sips, E. Villedieu, P. de Vries, M.L. Watkins, EFDA-JET Contributors, Phys. Scr. T145 (2011) 014001.

[5] A. Widdowson, E. Alves, C.F. Ayres, A. Baron-Wiechec, S. Brezinsek, N. Catarino, J.P. Coad, K. Heinola, J. Likonen, G.F. Matthews, M. Mayer, M. Rubel, JET-EFDA Contributors, Phys. Scr. T159 (2014) 014010.

[6] K. Heinola, A. Widdowson, J. Likonen, E. Alves, A. Baron-Wiechec, N. Barradas, S. Brezinsek, N. Catarino, P. Coad, S. Koivuranta, S. Krat, G.F. Matthews, M. Mayer, P. Petersson, JET Contributors, Phys. Scr. T167 (2016) 014075.

[7] J.P. Coad, H.-G. Esser, J. Likonen, M. Mayer, G. Neill, V. Philipps, M. Rubel, J. Vince, JETEFDA Contributors, Fusion Eng. Des. 74 (2005) 745-749.

[8] S. Krat, Y. Gasparyan, A. Pisarev, M. Mayer, U. von Toussaint, P. Coad, A. Widdowson, JETEFDA Contributors, J. Nucl. Mater. 463 (2015) 822-826.

[9] S. Krat, M. Mayer, U. Von Toussaint, P. Coad, A. Widdowson, Y. Gasparyan, A. Pisarev, JET Contributors, Nucl. Mater. Energy (2016) In press 10.1016/j.nme.2016.12.005.

[10] M. Rubel, G. De Temmerman, P. Sundelin, J.P. Coad, A. Widdowson, D. Hole, F. Le Guern, M. Stamp, J. Vince, JET-EFDA Contributors, J. Nucl. Mater. 390-391 (2009) 1006-1069.

[11] H.G. Esser, V. Philipps, M. Freisinger, P. Coad, G.F. Matthews, G. Neill, JET EFDA Contributors, Phys. Scr. T111 (2004) 129.

[12] J.P. Coad, D.E. Hole, M. Rubel, A. Widdowson, J. Vince, JET-EFDA Contributors, Phys. Scr. T138 (2009) 014023.

[13] J. Beal, A. Widdowson, K. Heinola, A. Baron-Wiechec, K.J. Gibson, J.P. Coad, E. Alves, B. Lipschultz, A. Kirschner, G.F. Matthews, S. Brezinsek, JET-EFDA Contributors, J. Nucl. Mater. 463 (2014).

[14] N. Catarino, A. Widdowson, A. Baron-Wiechec, J.P. Coad, K. Heinola, M. Rubel, E. Alves, JET Contributors, Submitted to Physica Scripta (2017).

[15] A. Kirschner, D. Matveev, D. Borodin, M. Airila, S. Brezinsek, M. Groth, S. Wiesen, A. Widdowson, J. Beal, H.G. Esser, J. Likonen, N. Bekris, R. Ding, JET-EFDA Contributors, J. Nucl. Mater. 463 (2015) 116-122.

[16] A. Widdowson, E. Alves, A. Baron-Wiechec, N.P. Barradas, N. Catarino, J.P. Coad, V. Corregidor, A. Garcia-Carrasco, K. Heinola, S. Koivuranta, S. Krat, A. Lahtinen, J. Likonen, M. Mayer, P. Petersson, M. Rubel, S. Van Boxel, JET Contributors, Nucl. Mater. Energy (2016) In press 10.1016/j.nme.2016.12.008.

[17] J. Beal, A. Widdowson, K. Heinola, A. Baron-Wiechec, K.J. Gibson, J.P. Coad, E. Alves, B. 
Lipschultz, A. Kirschner, H.G. Esser, G.F. Matthews, S. Brezinsek, JET Contributors, Phys. Scr. T167 (2016) 014052.

[18] A. Kreter, S. Brezinsek, J.P. Coad, H.G. Esser, W. Fundamenski, V. Philipps, R.A. Pitts, V. Rohde, T. Tanabe, A. Widdowson, JET-EFDA Contributors, J. Nucl. Mater. 390-391 (2009).

[19] J.F. Ziegler, J.P. Biersack, M.D. Ziegler, SRIM Textbook, n.d. 